\title{
ANALISIS KESIAPAN SERTIFIKASI KOMPETENSI PADA SUB KOMPETENSI KEMAMPUAN MENYUSUN LAPORAN KEUANGAN SESUAI DENGAN STANDAR AKUNTANSI KEUANGAN (SAK) BAGI MAHASISWA PRODI AKUNTANSI D3 FAKULTAS EKONOMI (FE) UNY BERDASARKAN SERTIFIKASI KEAHLIAN AKUNTANSI DASAR IKATAN AKUNTAN INDONESIA (IAI)
}

\section{THE ANALYSIS OF READINESS COMPETENCY CERTIFICATION IN SUB COMPETENCE TO PREPARE THE FINANCIAL REPORT BASEN ON FINANCIAL ACCOUNTING STANDARD FOR DIPLOMA STUDENTS OF ACCOUNTING DEPARTMENT IN FACULTY OF ECONOMIC YOGYAKARTA STATE UNIVERSIT BASED ON ACCOUNTING SKILLS CERTIFICATION EXAM (USKAD)}

\author{
Oleh : \\ Patriani Wahyu Dewanti \\ Jurusan Pendidikan Akuntansi Fakultas Ekonomi Universitas Negeri Yogyakarta \\ Patriani_wd@uny.ac.id
}

\begin{abstract}
Abstrak
Penelitian ini bertujuan untuk menganalisis kesiapan mahasiswa Program Studi Akuntansi D3 Fakultas Ekonomi UNY menghadapi uji sertifikasi kompetensi Akuntansi berdasarkan sertifikasi keahlian Akuntansi Dasar Ikatan Akuntan Indonesia (IAI) guna mendukung persaingan dalam dunia tenaga kerja di era globalisasi.

Penelitian ini termasuk penelitian observasi dengan populasi penelitian adalah mahasiswa Program Studi D3 FE UNY yang sedang menempuh studi semester V sejumlah 47 orang. Data yang dikumpulkan dalam penelitian ini adalah Dokumen Hasil Studi (DHS) berupa nilai mata kuliah terkait kompetensi yang diuji dalam sertifikasi keahlian Akuntansi Dasar Ikatan Akuntan Indonesia (IAI). Variabel dalam penelitian ini adalah kesiapan mahasiswa dalam menghadapi uji sertifikasi kompetensi di bidang Akuntansi Dasar (USKAD). Terdapat tiga kompetensi yang diuji dalam penelitian ini, yaitu mampu menyusun laporan keuangan; menyusun dan menyajikan laporan keuangan; dan melakukan analisis laporan keuangan. Penelitian ini hanya membahas salah satu sub kompetensi dari tiga kompetensi yang diujikan pada sertifikasi kompetensi di bidang Akuntansi Dasar (USKAD), yaitu kemampuan mahasiswa dalam menyusun laporan keuangan sesuai dengan Standar Akuntansi Keuangan (SAK). Analisis data penelitian menggunakan analisis statistik deskriptif dalam bentuk tabel kategorisasi kesiapan mahasiswa.

Hasil penelitian menunjukkan bahwa: (1) Sebanyak 48,9\% mahasiswa dikategorikan sangat siap; 21,3\% siap; 19,1\% cukup siap; dan 10,6\% kurang siap dalam menghadapi uji kompetensi menyusun laporan keuangan sesuai dengan Standar Akuntansi Keuangan (SAK).
\end{abstract}

Kata kunci: Sertifikasi Kompetensi, Sertifikasi Akuntansi, IAI

\section{Abstract}

This study aimed to analyze the readiness of Diploma Students (Associate Degree) of Accounting Department in Faculty of Economics Yogyakarta State University to face the certification of competencies based on certification issued by Indonesian Institute of Indonesia Chartered Accountants to deal with the competition in the era of globalization. The subjects of the research were 47 students of Diploma in Accounting 
Department, Faculty of Economics, Yogyakarta State University who are studying the fifth semester. Data collected in this research were the grade of each course in the List of Students Study Results (DHS) related with the competencies that will be tested in Accounting Skills Certification Exam (USKAD). The variable in this research is the readiness of the students to face the certification of competencies. There are three competencies tested in this research, which are the ability to prepare the financial statements based on accounting financial reporting standards, the ability to prepare and present the financial statements according to accounting cycle, and the ability to analyze financial reports. This study only discussed about the ability of the students to prepare the financial report based on Financial Accounting Standard. The research used descriptive statistical analysis to categorize the readiness of the student. The results showed that: 48,9\% of the students were categorized as well prepared; 21,3\% prepared; 19,1 less prepared; and 10,6\% unprepared to deal with the competency test preparing the financial statements.

Keywords: Competency Certification, Accounting Certification, IAI

\section{PENDAHULUAN}

Berdasarkan data Badan Pusat Statistik tahun 2014, 9,5\% (688.660 orang) dari total pengangguran di Indonesia merupakan alumni perguruan tinggi dengan ijazah Diploma (D3) dan Sarjana (S1). Banyaknya lulusan perguruan tinggi yang menganggur karena adanya ketimpangan antara kompetensi lulusan dengan tenaga kerja yang dibutuhkan oleh dunia usaha dan industri. Lulusan perguruan tinggi sedang mengalami dilema, sebab gelar ijazah tidak lagi menjadi jaminan untuk mendapatkan pekerjaan yang diimpikan. Mereka harus meningkatkan profesionalisme sebagai upaya menghadapi persaingan di dunia kerja.

Peningkatan kualitas tenaga kerja di bidang Akuntansi tidak terlepas dari peningkatan mutu Sumber Daya Manusia (SDM) yang mampu bekerja secara profesional. Kemampuan bekerja secara profesional diperoleh karena kompeten dalam menggunakan ilmunya saat melakukan pekerjaan. Tenaga kerja yang memiliki kompetensi dalam suatu bidang pengetahuan mempunyai kesempatan yang lebih luas dibandingkan dengan tenaga kerja yang hanya mengandalkan ijazah sebagai prasyaratnya. Hal ini sangat diperlukan dalam memperoleh kesempatan kerja di era persaingan global. Kesempatan kerja tidak hanya mencakup kawasan dalam negeri melainkan sampai ke luar negeri, terutama pada negara-negara di kawasan
ASEAN yang diimplementasikan pada Masyarakat Ekonomi ASEAN tahun 2015.

Program Diploma 3 (D3) atau disebut sebagai Pendidikan Vokasi merupakan salah satu jenjang pendidikan tinggi yang menghasilkan ahli madya di Indonesia. Program ini memiliki tujuan menyiapkan mahasiswanya untuk menjadi praktisi yang terampil untuk memasuki dunia kerja sesuai dengan bidang keahliannya. Oleh karena itu dalam rangka mempersiapkan lulusannya untuk menghadapi persaingan global, maka lembaga pendidikan perlu untuk meningkatkan kualitas lulusan program diploma agar memenuhi standar kualitas minimum profesionalisme yang dibutuhkan dalam dunia kerja. Berdasarkan hal tersebut lembaga pendidikan perlu melakukan langkah-langkah yang tepat untuk mendukung, seperti dilaksanakannya sertifikasi kompetensi bagi lulusan program diploma.

Berdasarkan Undang-Undang Republik Indonesia Nomor 20 tahun 2003 tentang Sistem Pendidikan Nasional (SNP). SNP terdiri atas standar isi, standar proses, standar kompetensi lulusan, standar tenaga kependidikan, standar sarana dan prasarana, standar pengelolaan, standar pembiayaan dan standar penilaian pendidikan yang harus ditingkatkan secara berencana dan berkala. Kompetensi lulusan diartikan merupakan kualifikasi kemampuan lulusan yang mencakup sikap, pengetahuan, dan keterampilan yang sesuai dengan standar 
nasional yang telah disepakati. Keberhasilan suatu lembaga pendidikan dapat diukur dari kualitas lulusannya. Adapun parameter tercapainya kualitas kelulusan adalah conformance dan performance (Machfoedz dalam Zulfikar, 2013).

Sertifikasi kompetensi diberikan kepada lulusan perguruan tinggi yang telah melaksanakan uji sertifikasi dan dinyatakan lulus yang artinya bahwa mereka kompeten sesuai dengan bidang yang dikuasai. Dengan dilaksanakannya ujian kompetensi maka lulusan perguruan tinggi selain mendapatkan ijazah yang menyatakan bahwa mereka telah menyelesaikan pendidikan tingkat perguruan tinggi mereka juga akan mendapatkan sertifikat kompetensi dari lembaga sertifikasi profesi.

Program Studi Akuntansi D3 Fakultas Ekonomi (FE) UNY sebagai salah satu lembaga pendidikan tinggi diharapkan juga mampu menghasilkan lulusan ahli madya yang bersaing dan memiliki kompetensi di bidang Akuntansi. Salah satu langkah yang dapat dilakukan adalah dengan merencanakan pelaksanakan uji kompetensi kepada mahasiswa sehingga mahasiswa dapat mengetahui kompetensi mereka di bidang Akuntansi.

Berdasarkan gambaran diatas, UNY melalui Fakultas Ekonomi (FE) sebagai lembaga pendidikan yang memiliki program studi Akuntansi D3 sudah seharusnya mengadakan program sertifikasi profesi supaya lulusannya memiliki nilai tambah saat bersaing dalam dunia kerja di era globalisasi. Tahap awal yang dapat dilakukan adalah melakukan pengkajian atas kesiapan mahasiswa dalam menghadapi uji sertifikasi kompetensi untuk menghadapi persaingan tenaga kerja dengan merujuk kepada sertifikasi yang dikeluarkan Ikatan Akuntan Indonesia (IAI) selaku organisasi profesional Akuntan yang menaungi seluruh Akuntan di Indonesia. Dengan melakukan pengkajian tersebut diharapkan dapat dijadikan pertimbangan pelaksanaan ujian sertifikasi kompetensi yang dapat mendukung lulusan
Prodi Akuntasi D3 menjadi tenaga ahli madya yang kompeten dibidangnya dan mampu bersaing dalam dunia kerja.

\section{Identifikasi Masalah}

Berdasarkan uraian sebelumnya, dapat diidentifikasi beberapa permasalahan sebagai berikut:

1. Berdasarkan data Badan Pusat Statistik tahun 2014, di Indonesia ada 9,5\% (688.660 orang) dari total pengangguran merupakan alumni perguruan tinggi dengan ijazah Diploma (D3) dan Sarjana (S1).

2. Banyaknya lulusan perguruan tinggi yang menganggur karena adanya ketimpangan antara kompetensi lulusan dengan tenaga kerja yang dibutuhkan (demand) oleh dunia usaha dan industri.

3. Sertifikasi kompetensi Vokasi atau Diploma untuk keahlian tertentu jumlahnya masih sangat kecil, terlebih untuk keahlian Akuntansi.

4. Lulusan Program Studi Akuntansi D3 FE UNY belum memiliki sertifikasi profesi sebagai nilai tambah untuk bersaing dengan lulusan perguruan tinggi lain yang telah mengadakan sertifikasi untuk program yang setara dalam dunia kerja di era globalisasi.

\section{Rumusan Masalah}

"Bagaimana kesiapan mahasiswa Prodi Akuntansi D3 FE UNY dalam menghadapi uji sertifikasi keahlian Akuntansi dasar Ikatan Akuntan Indonesia (IAI) pada sub kompetensi kemampuan menyusun laporan keuangan sesuai dengan Standar Akuntansi Keuangan (SAK)?”

\section{Tujuan Penelitian}

Penelitian ini bertujuan untuk menganalisis kesiapan mahasiswa Program Studi Akuntansi D3 FE UNY menghadapi uji sertifikasi keahlian Akuntansi dasar pada sub kompetensi kemampuan menyusun laporan keuangan sesuai dengan Standar Akuntansi 
Keuangan (SAK) guna mendukung persaingan di dunia kerja.

\section{Manfaat Penelitian}

Manfaat penelitian ini antara lain sebagai berikut:

a. Bagi Mahasiswa, hasil penelitian ini diharapkan dapat membantu memastikan penguasaan kompetensi yang dimiliki untuk meningkatkan rasa percaya diri dalam menghadapi persaingan di dunia kerja.

b. Bagi Stakeholder, khususnya pengambil kebijakan dalam hal ini adalah Pengelola D3 FE UNY, hasil penelitian ini diharapkan dapat menjadi rekomendasi untuk mengadakan sertifikasi kompetensi bagi mahasiswa Prodi Akuntansi D3 agar mampu bersaing di dunia kerja.

\section{Tinjauan Pustaka}

Kompetensi merupakan sesuatu yang menggambarkan kemampuan seseorang baik secara kualitatif maupun kuantitatif.. Kompetensi sangat penting bagi seorang indiividu, terutama pada sesorang yang terlibat dalam menekuni suatu pekerjaan (profesi), maka kompetensi merupakan sesuatu hal yang mendasar bagi terciptanya kualitas kerja yang dihasilkannya, sejalan dengan itu Spencer and Spencer (dalam Sumedi 2013) memberikan definisi bahwa kompetensi adalah..."an underlying characteristic of an individual that is causally related it criterion referenced effective and/or superior performance in job or situation". Menurut definisi tersebut, kompetensi merupakan karakteristik dsasar individu yang mempengaruhi efektivitas cara berfikir dan bertindak serta membentuk kinerja yang tinggi.

Keputusan Menteri Pendidikan Nasional Republik Indonesia Nomor 045/U/2002 Tentang Kurikulum Inti Pendidikan Tinggi, Pasal 1, menyatakan pengertian kompetensi adalah seperangkat tindakan cerdas, penuh tanggungjawab yang dimiliki seseorang sebagai syarat untuk dianggap mampu oleh masyarakat dalam melaksanakan tugas-tugas di bidang pekerjaan tertentu. Sedangkan pasal 2 ayat 1 menyatakan bahwa kompetensi hasil didik suatu program studi terdiri atas :

a. Kompetensi utama

b. Kompetensi pendukung

c. Kompetensi lain yang bersifat khusus dan gayut dengan kompetensi utama.

Sedangakan pasal 2 ayat 2 menyatakan bahwa elemen-elemen kompetensi terdiri atas :

a. Landasan kepribadian

b. Penguasaan ilmu dan ketrampilan

c. Kemampuan berkarya

d. Sikap dan perilaku dalam berkarya menurut tingkat keahlian berdasarkan ilmu dan ketrampilan yang dikuasai

e. Pemahaman kaidah berkehidupan bermasyarakat sesuai dengan pilihan keahlian dalam berkarya.

Menurut Taxonomi Bloom, pengertian kompetensi dapat di bagi menjadi tiga domain/ranah dan para trainer biasanya mengaitkan ketiga domain/ranah tersebut dengan Knowledge, Skill and Attitude (KSA), yaitu

1. Domain/Ranah kognitif, menekankan pada knowledge.

2. Domain/Ranah afektif, menekankan pada Atitude.

3. Domain/Ranah psikomotorik, menekankan pada Skill.

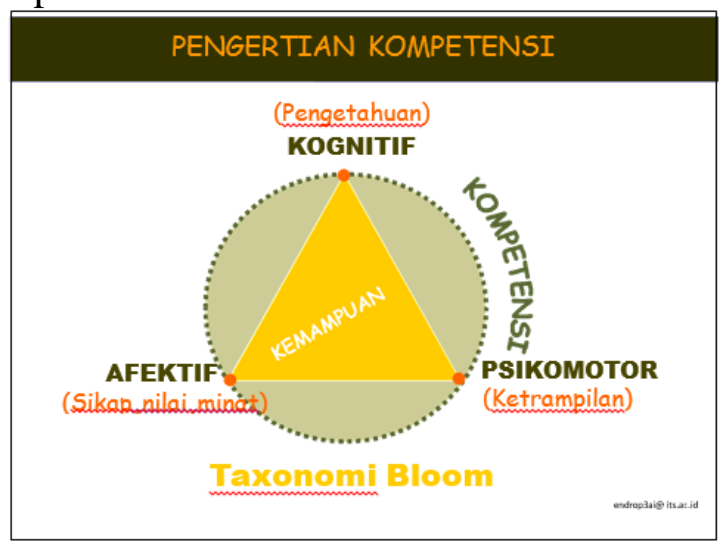

Gambar 1. Taxonomi Bloom 
Mohammed (2003), mengungkapkan bahwa dengan meningkatnya era globalisasi dan inovasi di era teknologi, menjadi suatu keharusan untuk seorang lulusan akuntansi untuk dapat bertahan dalam lingkungan pasar global:

1. Keahlian Komunikasi (communication skills)

2. Keahlian komputer (computer skills)

3. Keahlian analisis dan intelektual (analitycal and intelectual skills).

4. Multi-Disciplinary and Inter-Disciplinary Skills

5. Pengetahuan mengenai masalah global (Knowledge of Global Issues)

6. Kualitas personal (personal qualities)

7. Critical thinking

Accounting Education Change Commission [AECC] menyarankan sistem pendidikan akuntansi yang mampu menghasilkan lulusan yang "utuh" sebagai tenaga profesional (IAI dalam Arianto dan Tarmizi, 2013). Untuk mencapai sasaran tersebut, yang diperlukan tidak semata-mata pengetahuan akuntansi dan pengetahuan bisnis yang relevan dengan akuntansi, tetapi juga keahlian atau skills, yang meliputi intellectual skills, interpersonal skills, dan communication skills, dan orientasi profesional.

Di Indonesia, sebagai tanggapan atas dikeluarkannya standar pendidikan internasional (International Education Standards/IES) oleh International Federation of Accountants (IFAC) Ikatan Akuntan Indonesia (IAI) berencana untuk memasukkan mata kuliah di luar akuntansi untuk dijadikan kurikulum inti yang bertujuan membangun soft skill penunjang (khususnya pada personal skill, interpersonal and communication skill, dan organizational and business skill) (IAI dalam Arianto dan Tarmizi, 2013).

Ditujukan IES ini kepada Akuntan publik yang bertugas mengaudit, bukan berarti bahwa semua yang dijelaskan dan tertera pada
IES adalah sesuatu yang tidak harus dimiliki oleh semua akuntan. Akuntan diharapkan menjadi seorang yang professional dan berintegritas. Akuntan merupakan professional yang dihasilkan lewat pelatihan dan pendidikan yang bekesinambungan, dan mempunyai standar produk yang sama yang salah satunya bersumber pada IES.

Dari beberapa pernyataan lembaga yang berkompeten dalam profesi Akuntansi di atas mengindikasikan bahwa ada arah untuk memperketat kualitas input, dalam hal ini mahasiswa Akuntansi. Diharapkan, mahasiswa Akuntansi memiliki skills yang berkualitas dengan tetap menjunjung tinggi nilai-nilai moral dan kode etik yang berlaku. Sebagaimana yang dimaksud diharapkan akan membuat citra profesi Akuntansi membaik dikarenakan jika profesi Akuntansi atau pekerjaan yang berkaitan dengan Akuntansi lainnya dilakukan oleh seorang yang mempunyai skill bagus dan menjunjung nilai moral dan etika atau dengan kata lain memenuhi standar IES ini, maka dengan sendirinya Akuntansi akan menjadi sebuah alat yang bermanfaat bagi dunia bisnis dan pada akhirnya akan berefek baik ke perekonomian secara umum.

Menurut Peraturan Pemerintah (PP) No. 23 Tahun 2004 tentang Badan Nasional Sertifikasi Profesi (BNSP) menjelaskan tentang sertifikasi kompetensi kerja sebagai suatu proses pemberian sertifikat kompetensi yang dilakukan secara sistematis dan objektif melalui uji kompetensi yang mengacu kepada standar kompetensi kerja nasional Indonesia atau Internasional.

Ikatan Akuntan Indonesia (IAI) adalah organisasi profesional Akuntan yang menaungi seluruh akuntan di indonesia dan mendapat kepercayaan dari pemerintah untuk menetapkan SAK, dan bertanggung jawab meningkatkan pengetahuan dan kehalian masyarakat dalam bidang akuntansi. Sebutan IAI dalam Bahasa Inggris adalah Institute of Indonesia Chartered Accountants. IAI menjadi satu-satunya wadah 
yang mewakili profesi akuntan Indonesia secara keseluruhan, baik yang berpraktik sebagai akuntan sektor publik, akuntan sektor privat, akuntan pendidik, akuntan publik, akuntan manajemen, akuntan pajak, akuntan forensik, dan lainnya. Selain itu IAI juga menyelenggarakan Ujian Sertifikasi Keahlian Akuntansi Dasar (USKAD) yang ditujukan untuk para mahasiswa aktif jurusan akuntansi dan pendidikan akuntansi yang memerlukan kualifikasi keahlian dasar di bidang Akuntansi.

Tujuan diadakannya ujian sertifikasi ini yaitu agar mahasiswa memiliki kemampuan serta keahlian di bidang akuntansi, mampu melaksanakan tugas operasional di bidang akuntansi, mampu menganalisa transaksi keuangan serta menerapkan ilmu pengetahuannya untuk melaksanakan praktik di bidang akuntansi. Peserta USKAD disyaratkan memiliki ijazah minimal setingkat SMA/SMK sederajat dari semua jurusan dan tercatat sebagai mahasiswa aktif jurusan akuntansi atau pendidikan akuntansi serta vokasi program studi akuntansi. USKAD adalah ujian untuk mengukur keahlian peserta dalam hal berikut :

1. Memahami dan menjelaskan kerangka dasar penyusunan dan penyajian laporan keuangan sesuai dengan Standar Akuntansi Keuangan (SAK).

2. Mengidentifikasi transaksi-transaksi yang terdapat dalam laporan keuangan.

3. Menyusun dan menyajikan laporan keuangan sesuai dengan siklus akuntansi.

4. Melakukan analisa dasar Laporan Keuangan

\section{METODE PENELITIAN}

\section{Waktu dan Lokasi Penelitian}

Penelitian dilaksanakan selama 6 bulan mulai dari bulan Juni - November 2016. Lokasi penelitian dilakukan di Prodi Akuntansi D3 FE UNY yang berlokasi di Kampus Wates. Subjek penelitian ini adalah mahasiswa yang sedang menempuh studi semester V di Prodi Akuntansi D3 FE UNY yang berjumlah 47 orang.

\section{Desain Penelitian}

Penelitian ini termasuk jenis penelitian observasi, yang bertujuan untuk menguji pertanyaan penelitian tentang kesiapan mahasiswa Prodi Akuntansi D3 FE UNY untuk mengikuti Ujian Sertifikasi Keahlian Akuntansi Dasar (USKAD) yang diselenggarakan oleh Ikatan Akuntan Indonesia (IAI). Pertanyaan penelitian dikembangkan berdasarkan tinjauan pustaka dan penelitian-penelitian yang relevan terkait dengan faktor-faktor yang mempengaruhi kesiapan mahasiswa untuk mengikuti USKAD yang diselenggarakan oleh IAI.

\section{Variabel Penelitian}

Variabel yang diteliti pada penelitian ini adalah kesiapan mahasiswa untuk mengikuti USKAD yang diselenggarakan oleh IAI dengan cara melakukan pencermatan atas Daftar Hasil Studi (DHS) mahasiswa semester 5 (lima) Prodi Akuntansi FE UNY dan menentukan mata kuliah yang sesuai dengan standar kompetensi USKAD yang telah ditentukan oleh IAI .

Adapun definisi operasional dari variabel tersebut adalah sebagai berikut :

1. Dokumen Hasil Studi (DHS)

Dokumen hasil studi (DHS) merupakan daftar nilai mata kuliah yang telah ditempuh mahasiswa dan disahkan oleh Ketua Jurusan Pendidikan Akuntansi FE UNY. DHS diukur dengan melakukan pencermatan dokumen setiap mahasiswa semester 5 atas standar kompetensi yang akan diujikan di USKAD. Terdapat tiga kompetensi yang diujikan di USKAD, yaitu mampu menyusun laporan keuangan; menyusun dan menyajikan laporan keuangan; dan melakukan analisis laporan keuangan.

2. Standar Kompetensi

Standar kompetensi merupakan deskripsi pengetahuan, keterampilan, dan sikap yang harus dikuasai seorang mahasiswa dalam mempelajari program pembelajaran tertentu pada jenjang pendidikan tertentu pula. 
Standar kompetensi diukur dengan menentukan mata kuliah berdasarkan struktur kurikulum dan sebaran mata kuliah yang telah ditetapkan oleh Prodi Akuntansi D3 Fakultas Ekonomi Universitas Negeri Yogyakarta yang sesuai dengan standar kompetensi USKAD yang telah ditetapkan oleh IAI. Standar kompetensi pada sub kompetensi menyusun laporan keuangan sesuai dengan Standar Akuntansi Keuangan (SAK) dengan sebaran mata kuliah yang memenuhi adalah sebagai berikut:

Tabel 1. Standar Kompetensi dan Sebaran Mata Kuliah

\begin{tabular}{|c|c|}
\hline Kompetensi & Mata Kuliah \\
\hline $\begin{array}{l}\text { Mampu } \\
\text { menyusun } \\
\text { laporan } \\
\text { keuangan } \\
\text { sesuai dengan } \\
\text { Standar } \\
\text { Akuntansi } \\
\text { Keuangan } \\
\text { (SAK) }\end{array}$ & $\begin{array}{l}\text { 1. Akuntansi Pengantar I } \\
\text { 2. Akuntansi Pengantar II } \\
\text { 3. Akuntansi Keuangan } \\
\text { Menengah I } \\
\text { 4. Akuntansi Keuangan } \\
\text { Menengah II } \\
\text { 5. Akuntansi Keuangan } \\
\text { Lanjutan } \\
\text { 6. Praktikum Akuntansi } \\
\text { Pengantar } \\
\text { 7. Praktikum Akuntansi } \\
\text { Keuangan Menengah I } \\
\text { 8. Praktikum Akuntansi } \\
\text { Keuangan Menengah II } \\
\text { 9. Praktikum Akuntansi } \\
\text { Keuangan Lanjutan }\end{array}$ \\
\hline
\end{tabular}

\section{Sampel Penelitian}

Populasi penelitian ini adalah mahasiswa Prodi Akuntansi D3 FE UNY. Pengambilan sampel dalam penelitian ini dilakukan dengan menggunakan metode purposive sampling (pemilihan sampel bertujuan) diperoleh sampel berjumlah 47 mahasiswa. Kriteria pemilihan sampel adalah sebagai berikut :

a. Mahasiswa yang terdaftar di Prodi Akuntansi D3 FE UNY. b. Telah menempuh studi di semester 5 .

\section{Jenis Data}

Jenis data yang digunakan merupakan data yang dapat diukur secara langsung atau lebih tepatnya dapat dihitung, sehingga data yang digunakan adalah data sekunder dan merupakan data kuantitatif.

\section{Metode Pengumpulan Data}

Metode pengumpulan yang digunakan untuk mengumpulkan data terkait variabel penelitian adalah metode dokumentasi. Data diperoleh dari bagian akademik dan pengelola Prodi Akuntansi D3 FE UNY.

\section{Instrumen dan Uji Instrumen}

Instrumen penelitian berupa daftar yang dipakai untuk menghitung nilai mahasiswa dengan mengalikan nilai mata kuliah dengan skala penilaian masing-masing nilai. Data yang digunakan adalah Dokumen Hasil Studi (DHS) dan Struktur kurikulum D3 Prodi Akuntansi FE UNY.

\section{Teknik Analisis Data}

Analisis data penelitian dengan menggunakan analisis statistik deskriptif. Analisis data ini hanya berupa akumulasi data dasar dalam bentuk deskripsi semata. Dalam penelitian ini statistik deskriptif digunakan untuk menyajikan data hasil penilaian yakni pencermatan atas Dokumen Hasil Studi (DHS) dengan standar kompetensi USKAD dari IAI dengan menggunakan mean ideal (Mi) dan standar deviasi ideal (SDi). Untuk mengetahui pola kecenderungan data, maka data dikategorikan menggunakan teknik yang digunakan oleh Sutrisno Hadi (2016). Teknik tersebut membagi data dalam beberapa kategori sehingga dapat digolongkan dalam kelompok tertentu.

Penentuan mean ideal dan deviasi standar ideal dapat digunakan rumus sebagai berikut: 


$$
\begin{aligned}
& \mathrm{Mi}=[\mathrm{ST}+\mathrm{SR}]: 2 \\
& \mathrm{SDi}=[\mathrm{ST}-\mathrm{SR}]: 6
\end{aligned}
$$

Keterangan:

$\begin{array}{ll}\text { Mi } & \text { : Mean ideal } \\ \text { SDi } & \text { : Standar Deviasi ideal } \\ \text { ST } & \text { : Skor ideal tertinggi } \\ \text { SR } & \text { : Skor ideal terendah }\end{array}$

Setelah diperoleh nilai mean ideal dan deviasi standar ideal maka data dapat di kategorikan menjadi lima kategori sebagai berikut:

Kategori Sangat Siap : X $>\mathrm{Mi}+1,5 \mathrm{SDi}$

Kategori Siap $\quad: \mathrm{Mi}<\mathrm{X} \leq \mathrm{Mi}+1,5 \mathrm{DSi}$

Kategori Cukup Siap : Mi $-1,5 \mathrm{SDi}<\mathrm{X} \leq \mathrm{Mi}$

Kategori Kurang Siap : < Mi - 1,5 SDi

\section{HASIL PENELITIAN DAN PEMBAHASAN Hasil Penelitian}

Penelitian dilakukan dengan mencermati DHS setiap mahasiswa atas nilai dari mata kuliah yang terkait dengan kompetensi yang diujikan dalan Ujian Sertifikasi Keahlian Akuntansi Dasar (USKAD). Pengukuran kesiapan sertifikasi kompetensi mahasiswa dilakukan dengan menghitung rerata nilai pada setiap kompetensi, kemudian dari rerata tersebut dikelompokkan sesuai dengan kategori penilaian yaitu Sangat Siap, Siap, Cukup Siap, dan Kurang Siap. Pada sub kompetensi menyusun laporan keungn sesuai Standar Akuntansi Keuangan (SAK), pembahasan terkait temuan dijabarkan sebagai berikut:

Hasil penelitian menunjukkan mean 3,65 dengan skor tertinggi (ST) yang dicapai adalah 4,00 dan skor terendah (SR) 2,96. Untuk mengetahui kecenderungan kompetensi mahasiswa, digunakan mean ideal (Mi) dan standar deviasi ideal (SDi).

$$
\begin{aligned}
\mathrm{Mi} & =1 / 2(\mathrm{ST}+\mathrm{SR}) \\
& =1 / 2(4,00+2,96)=3,4821 \\
\mathrm{SDi} & =1 / 6(\mathrm{ST}-\mathrm{SR}) \\
& =1 / 6(4,00-2,96)=0,1726
\end{aligned}
$$

\begin{tabular}{|c|c|c|c|c|}
\hline No. & Kategori & Rentang & Jumlah & $\begin{array}{l}\text { Persen- } \\
\text { ase }\end{array}$ \\
\hline 1 & $\begin{array}{l}\text { Sangat } \\
\text { Siap }\end{array}$ & $>3,74$ & 23 & $48,9 \%$ \\
\hline 2 & Siap & $\begin{array}{l}3,48- \\
3,74\end{array}$ & 10 & $21,3 \%$ \\
\hline 3 & $\begin{array}{l}\text { Cukup } \\
\text { Siap }\end{array}$ & $\begin{array}{l}3,22- \\
3,48 \\
\end{array}$ & 9 & $19,1 \%$ \\
\hline 4 & $\begin{array}{l}\text { Kurang } \\
\text { Siap }\end{array}$ & $<3,22$ & 5 & $10,6 \%$ \\
\hline \multicolumn{3}{|c|}{ Jumlah } & 47 & $100,0 \%$ \\
\hline
\end{tabular}

Berdasarkan Mi dan SDi dapat diidentifikasi kompetensi yang dicapai mahasiswa sebagai berikut:
Tabel 2. Kategorisasi Kompetensi Menyusun Laporan Keuangan sesuai SAK

\section{Pembahasan}

Berdasarkan hasil penelitian, maka diperoleh bahwa mahasiswa Program Studi Akuntansi D3 belum sepenuhnya memenuhi kompetensi Sertifikasi Keahlian Akuntansi dasar. Namun, dari data yang diperoleh, sebagian besar mahasiswa dianggap telah siap untuk mengikuti sertifikasi pada sub kompetensi menyusun laporan keuangan sesuai dengan SAK.

Standar kompetensi ini menguji pemahaman mahasiswa mengenai proses akuntansi yang terdiri dari pencatatan transaksi hingga proses penyusunan laporan keuangan yang sesuai dengan SAK serta pemahaman lanjut tentang pos-pos yang ada di dalam laporan keuangan. Berdasarkan sebaran mata kuliah dalam struktur kurikulum D3 Prodi Akuntansi, terdapat 7 mata kuliah yang terkait dengan kompetensi ini. Berdasarkan hasil penelitian, sebanyak 23 mahasiswa atau 48,9\% dengan rentang >3,74 dikategorikan sangat siap dan 5 mahasiswa dikategorikan kurang siap atau $10,6 \%$ dengan rentang $<3,22$. Sehingga dapat dikatakan bahwa hampir $50 \%$ dari mahasiswa telah memiliki pengetahuan dan kemampuan yang baik untuk menyusun laporan keuangan sesuai dengan SAK dan sangat siap untuk mengikuti uji kompetensi USKAD dengan 
standar kompetensi menyusun laporan keuangan sesuai dengan SAK.

\section{SIMPULAN DAN SARAN Simpulan}

Terdapat tiga kompetensi yang diteliti dalam penelitian ini yaitu kemampuan menyusun laporan keuangan sesuai dengan Standar Akuntansi Keuangan (SAK), menyusun dan menyajikan laporan keuangan sesuai dengan siklus akuntansi, dan melakukan analisis laporan keuangan. Pada sub kompetensi menyusun laporan keuangan sesuai Standar Akuntansi Keuangan (SAK) dapat disimpulkan bahwa sebanyak 23 mahasiswa D3 Prodi Akuntansi FE UNY atau $48,9 \%$ dikategorikan sangat siap dalam menghadapi uji kompetensi berupa penyusunan laporan keuangan sesuai dengan SAK. Sedangkan mahasiswa yang dikategorikan kurang siap hanya terdiri dari sebagian kecil saja yaitu 5 mahasiswa atau $10,6 \%$.

\section{Saran}

Berdasarkan kesimpulan-kesimpulan diatas, saran yang dapat diberikan adalah

1. Pada sub bab standar kompetensi menyusun laporan keuangan sesuai Standar Akuntansi Keuangan (SAK) 2 mata kuliah yang sedang diambil oleh mahasiswa di semester V ini, yaitu praktikum akuntansi keuangan menengah 2 dan praktikum akuntansi keuangan lanjutan, oleh karena itu nilai kedua mata kuliah tersebut belum dimasukkan ke tabulasi data.

2. Dari hasil analisis data dapat dikatakan bahwa mahasiswa D3 Prodi Akuntansi FE UNY semester $V$ sangat siap untuk mengikuti uji kompetensi USKAD pada sub kompetensi menyusun laporan keuangan sesuai Standar Akuntansi keuangan (SAK). Hal ini dapat menjadi pertimbangan bagi pengambil kebijakan agar mempertimbangkan pelaksanaan Ujian Sertifikasi Keahlian Akuntansi Dasar (USKAD) bagi mahasiswa D3 Prodi
Akuntansi FE UNY agar dapat menjadi nilai tambah bagi lulusan D3 Prodi Akuntansi FE UNY dalam dunia kerja dan dalam menghadapi persaingan global.

\section{DAFTAR PUSTAKA}

Anonim, 2014, Pengangguran terbuka Menurut Pendidikan Tertinggi yang Ditamatkan 2004-2014, dalam tautan www.BPS.go.id

Anonim, 2016, Sekilas BNSP, dalam tautan www.bnps.go.id.

Anonim, 2016, Keuntungan Sertifikasi, dalam tautan www.bnps.go.id.

Anonim, 2016, Masyarakat Ekonomi

Asean, dalam tautan

www.wikipedia.co.id.

Awayiga, Joseph Y., Joseph M. Onumah, and Mathew Tsamenyi. "Knowledge and skills development of accounting graduates: The perceptions of graduates and employers in Ghana." Accounting Education: an international journal 19.1-2 (2010): 139-158.

Kementrian Pendidikan Nasional. Standar Kompetensi Lulusan Akuntansi, 2011.

Hutapea, Parulian, and M. B. A. Nurianna Thoha. Kompetensi plus. Gramedia Pustaka Utama, 2008.

Hadi, Sutisno. Metodologi Riset. Pustaka Pelajar, 2016.

Kavanagh, Marie H., and Lyndal Drennan. "What skills and attributes does an accounting graduate need? Evidence from student perceptions and employer expectations." Accounting \& Finance 48.2 (2008): 279-300.

Mohammed, Ehab K.A. "Accounting Knowledge and Skills and the Challenges of A Global Business 
Jurnal Pendidikan Akuntansi Indonesia, Vol. XIV, No. 2, Tahun 2016

Patriani Wahyu Dewanti

$117-126$

Environment", Emerald Insight, Vol 29

Number 7, 2003.

Community., Seminar Nasional IENACO. (2015)

Setyaningsih, Ira. Kompetensi Untuk Menakar

Kesiapan Mahasiswa Menghadapi

Tarmizi, Tashadi. "Kajian Spesifikasi Keahlian

Persaingan Asean Economic Akuntansi pada Kurikulum Penyelenggara Program Diploma 3 Akuntansi di Indonesia." (2015) 